Aus diesen Ergebnissen geht hervor, daß die mit Trichloressigäure erzeugten Niederschläge viel zu niedrige Werte ergeben.

Die mit Quecksilberchlorid erzeugten Fällungen zeigen bessere Ergebnisse. Zwar werden auch mit diesem Reagens nicht sämtliche durch Zinksulfat fällbaren Proteosen ausgefällt, doch stimmen die erhaltenen Werte annähernd mit ihnen überein. Leim dagegen gibt unter gleichen Verhältnissen mit Quecksilberchlorid überhaupt keine Fällung.

Das $Q$ uecksilberjodid verhält sich umgekehrt wie Quecksilberchlorid; es fällt eher Leim als Proteosen. Enthält also die Fällung mit Quecksilberchlorid annähernd soviel Stickstoff als die Fällung mit Zinksulfat, so ist kein Leim anzunehmen; ist dagegen die Differenz erheblich, so ist die Anwesenheit von Leim wahrscheinlich.

In letzterem Falle kann dann die Fällung mit Quecksilberjodid zur Erhärtung dieses Ergebnisses dienen. Enthält der Niederschlag hiermit, im Verhältnis zu dem durch Zinksulfat erhaltenen, viel Stickstoff, oder ist der im Filtrat erhaltene Stickstoff verhältnismäßïg viel niedriger als im Zinksulfat-Niederschlage, so ist die Anwesenheit von Leim als erwiesen anzunehmen.

Mehr als einen qualitativen Nachweis und eine annähernde quantitative Bestimmung des Leimes durch die letzten Fällungsmittel zu erbringen, ist bis jetzt nicht möglich.

\title{
Beitrag zur colorimetrischen Bestimmung von Salicylsäure und Kupfer.
}

\author{
Von Dr. F. Schott.
}

Mitteilungaus dem Kantonalen Laboratorium in Lausane.

[Eingegangen am 1. November 1911.]

H. C. Sherman und A. GroB') empfehlen die Jorissen'sche Reaktion auf Salicylsäure als Kontrollprobe der Eisenchloridreaktion, besonders weil erstere nach dieser angewendet werden kann: „Zu der zu untersuchenden Lösung werden je 5 Tropfen 10\%-ige Kaliumnitritlösung und 50\%-ige Essigsäure, sowie ein Tropfen 10\%-ige Kupfersulfatlösung gegeben und $3 / 4$ Stunden auf dem Wasserbade erwärmt. Die entstandene Rotfärbung bleibt nach dem Abkühlen beständig“.

Dieses Verhalten mußte es als aussichtsreich erscheinen lassen, die Reaktion zur colorimetrischen Bestimmung von Salicylsäure und Kupfer zu verwerten.

\section{Salicylsäure.}

In gleich weite Röhrchen, die bei $5 \mathrm{ccm}$ eine Marke haben, werden a) die zu untersuchende Lösung, b) als Typlösungen $0,0,2,0,4,0,6,0,8,1,0$ etc. ccm einer $100 \mathrm{mg}$ im Liter enthaltenden Salicylsäurelösung gefüllt. Hierzu werden $2 \mathrm{cem}$ einer 10 -fach verdünnten Fehling'schen Kupfersulfatlösung und je 5 Tropfen $2 \%$-ige Kaliumnitritlösung und 10\%-ige Essigsäure gegeben und zur Marke aufgefüllt. Nach dreiviertel-

1) Journ. of Ind. and Engin. Chemisky 1911, 3, 492. 
stündigem Exhitzen im Wasserbade wird abgekühlt und verglichen. Ist die Färbung der zu untersuchenden Flüssigkeit sehr stark, so kann sie mit ungefähr gleichstark gefärbten Typen nach gleich starkem Verdünnen direkt oder in einem Colorimeter verglichen werden.

In Milch (analog auch in Butter) lassen sich größere Mengen Salicylsäure ohne Ätherausschüttelung folgendermaBen nachweisen: $\mathrm{Zu} 25 \mathrm{ccm}$ Milch werden $10 \mathrm{ccm}$ Fehlin g'sche Kupfersulfatlösung und soviel N.-Natronlauge gegeben, dala die Flüssigkeit nur noch ganz schwach sauer ist (etwa 1,5-2,0 $\mathrm{scm}$ ). Vom schwach grünblau gefärbten Filtrat werden $15 \mathrm{ccm}$ mit je 5 Tropfen 10\%-iger Kaljumnitritlösung und $50 \%$-iger Essigsäure versetzt und wie beschrieben behandelt. Bei einem salicylsäurefreiem Serum bleibt die Färbung unverändert, während bereits bei einem Gehalt von $10 \mathrm{mg}$ Salicylsäure im Liter Verfärbung eintritt. Zum colorimetrischen Vergleich. werden je $25 \mathrm{ccm}$ reine Milch mit $0,0,5,1,0,2,0,4,0, \mathrm{mg}$ Salicylsäure (entsprechend $0,20,40,80,160 \mathrm{mg}$ im Liter) versetzt und wie oben behandelt.

\section{Kupfer.}

In die Röhrchen werden a) die zu untersuchende Lösung b) als Typlösungen $0,0,1,0,2,0,4,0,6,0,8$ etc. ccm einer $100 \mathrm{mg} \mathrm{Kupfer} \mathrm{(}=0,3927 \mathrm{~g} \mathrm{CuSO}_{4}, 5 \mathrm{aq}$.) im Liter enthaltenden Kupfersulfatlösung gefüllt. Hierzu werden $0,3 \mathrm{ccm}$ einer $1 / 20 / 0$-igen wässerig-alkoholischen Salicylsäurelösung und je 5 Tropfen $2 \%$-ige Kaliumnitritlösung und 10\%-ige Essigsäure gegeben und auf die Marke aufgefüllt. Weiterhin wird, wie bei der Salicylsäurebestimmung angegeben ist, verfahren. Die blinde Typlösung ist gelb.

Dieser Kupfernachweis, bei dem noch Mengen von $0,01 \mathrm{mg}$ bestimmt werden können, ist weniger empfindlich als die Guajac-Blausäure-Reaktion. Aber erstens ist diese nicht für Kupfer charakteristisch, und zweitens kommt ihr die für die colorimetrische Bestimmung notwendige Beständigkeit der Färbung (blau) nicht zu, während die Rot-Färbung der Jorissen'schen Reaktion beständig ist. Die Methode ist hauptsächlich geeignet zur Bestimmung sehr kleiner Kupfermengen, wie sie z. B. in Trinkbranntweinen vorkommen. Bei extraktfreien Branntweinen kann der Rückstand der Destillation für die Alkoholbestimmung direkt nach dem Einengen verwertet werden. Bei extrakthaltigen Branntweinen ist der Rückstand der Aschebestimmung mit etwas Salpetersäure-Schwefelsäure-Mischung anzufeuchten, abzurauchen und mit wenig essigsäurehaltigem Wasser aufzunehmen.

Saccharose, Glykose, Milchzucker und Invertzucker stören die Reaktion nicht, wohl aber freie Mineralsäuren, Weinsäure und Citronensäure. Spuren von Eisen stören nicht, wohl aber größere Mengen. Auf jeden Fall ist es zweckmäßiger, das Eisen in der Wärme mit Ammoniak auszufüllen und unter Umständen den Niederschlag nochmals zu lösen und zu fällen. In den Filtraten wird das Ammoniak durch Eindampfen verjagt und mit verdünnter Essigsäure aufgenommen. 